\title{
Fault geometry and slip distribution of the 2003 Tokachi-oki earthquake as deduced from teleseismic body waves
}

\author{
Haruo Horikawa \\ Active Fault Research Center, National Institute of Advanced Industrial Science and Technology, Tsukuba, Ibaraki 305-8567, Japan
}

(Received November 30, 2003; Revised July 16, 2004; Accepted September 29, 2004)

\begin{abstract}
I have analyzed teleseismic body waves from the 2003 Tokachi-oki earthquake $\left(\mathrm{M}_{\mathrm{w}} 8.1\right)$, and inferred the slip distribution. Two simple fault models are assumed for estimating the effect of fault geometry on derived slip distributions. One is a single planar fault with a dip of $20^{\circ}$ and the other is a compound fault having a shallow plane with a dip of $5^{\circ}$ and deeper, landward plane with a dip of $20^{\circ}$. The compound-fault model is preferable because it explains the initial part of the observed P-waves better. It is found that the planar fault has one asperity (patch of large slip) near the hypocenter and the other asperity to the landward side of the hypocenter. The compound-fault model shares the landward asperity with the planar-fault model, but does not have the asperity near the hypocenter. The other asperity on the compound fault is found far from the hypocenter. This difference of the slip distributions suggests the importance of accurate modeling of the fault dip angle when deducing the slip distribution from teleseismic body waves.
\end{abstract}

Key words: Tokachi-oki earthquake, inversion analysis, slip distribution, fault geometry, dip angle, teleseismic body waves.

\section{Introduction}

Teleseismic body waves are often analyzed for constructing a source model of a subduction-zone earthquake (e.g., Lay and Wallace, 1995). A causative fault of a subductionzone earthquake (i.e., plate interface) usually dips gently, and a reverse-slip component is dominant on the fault. This means that the auxiliary plane dips steeply, and the teleseismic body waves are often radiated near the nodal line. This is because the seismic ray of teleseismic distances emerge from a seismic source with a small take-off angle which is nearly vertical. In such a case, a change in dip angle will not only alter the polarity of the initial motions but also the amplitude of the body waves. This suggests that modeling of the dip angle heavily biases slip distribution on a fault. It is important to estimate the degree of this bias because teleseismic body waves are still major data for investigating the source processes of earthquakes that occur in the region where few near-source seismological and/or geodetic data are available.

The 2003 Tokachi-oki earthquake occurred along the southern Kurile trench (Fig. 1), and provides a good opportunity for this estimation because detailed analysis of aftershock distribution will give much information on the fault configuration in the near future. However, the depth of the dip angle is not fully known in the source region so far. A seismic refraction survey conducted by Iwasaki et al. (1989) revealed the velocity structure and the shape of the plate interface in a shallower part (depth $<20 \mathrm{~km}$ ) of the source region, but the velocity structure and the shape

Copy right(c) The Society of Geomagnetism and Earth, Planetary and Space Sciences (SGEPSS); The Seismological Society of Japan; The Volcanological Society of Japan; The Geodetic Society of Japan; The Japanese Society for Planetary Sciences; TERRAPUB. of the plate interface below the depth is not well-known. Hence, I have assumed two simple source models in this paper. One is a planar fault which is common in body-wave analysis and the other is a new compound-fault which is proposed here. As shown later, different slip distributions are obtained from these two fault models.

\section{Data}

Twenty-four broad-band seismograms provided by the Incorporated Research Institutions for Seismology (IRIS) are analyzed in this study. Stations whose epicentral distance ranges from 30 to $90^{\circ}$ were chosen because the body waves observed within this range are not heavily contaminated by the Earth's structure such as complexity in the upper mantle (e.g., Lay and Wallace, 1995). Hence they are suitable for constructing a fault model. Besides the range of the epicentral distance, I have also taken account of the azimuthal coverage so that the azimuthal distribution of the stations could be as uniform as possible (Fig. 2).

In this study P-waves are modeled. The instrumental responses were deconvolved from the observed $\mathrm{P}$-waves, and the deconvolved waveforms were band-pass filtered between 0.01 and $0.4 \mathrm{~Hz}$. The time length of the data was taken to be $100 \mathrm{~s}$ from the onset of P-waves for all stations.

On the other hand, S-waves are not modeled. Correct timing of the waveforms is crucial in the inversion of teleseismic data (Hartzell and Heaton, 1983). It is not possible to pick $\mathrm{S}$ arrivals as accurately as $\mathrm{P}$ arrivals because the onset of an S-wave is generally emergent and sometimes contaminated by other seismic signals. Hence, the use of $\mathrm{S}$-waves which are misidentified at their onset may bias the estimated slip distribution. 


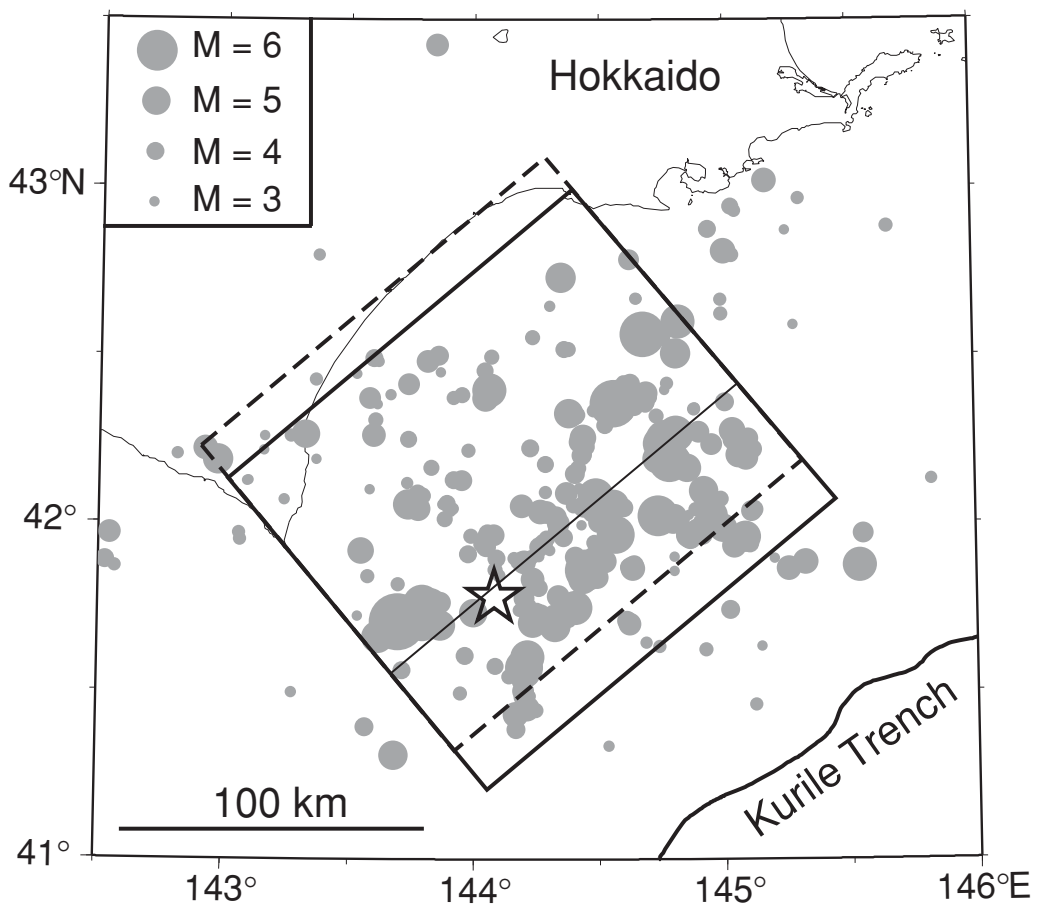

Fig. 1. Map showing the one-month aftershock distribution associated with the 2003 Tokachi-oki earthquake (gray circles) and the locations of the faults assumed in this study. Earthquakes of $\mathrm{M}>3$ and shallower than $100 \mathrm{~km}$ are plotted. The epicenter of the mainshock is displayed with a star. Dashed and solid bold lines stand for the planar fault and compound fault, respectively. The compound fault has a shallow plane with a dip of $5^{\circ}$ and deeper, landward plane with a dip of $20^{\circ}$. A thin line represents the hinge line.

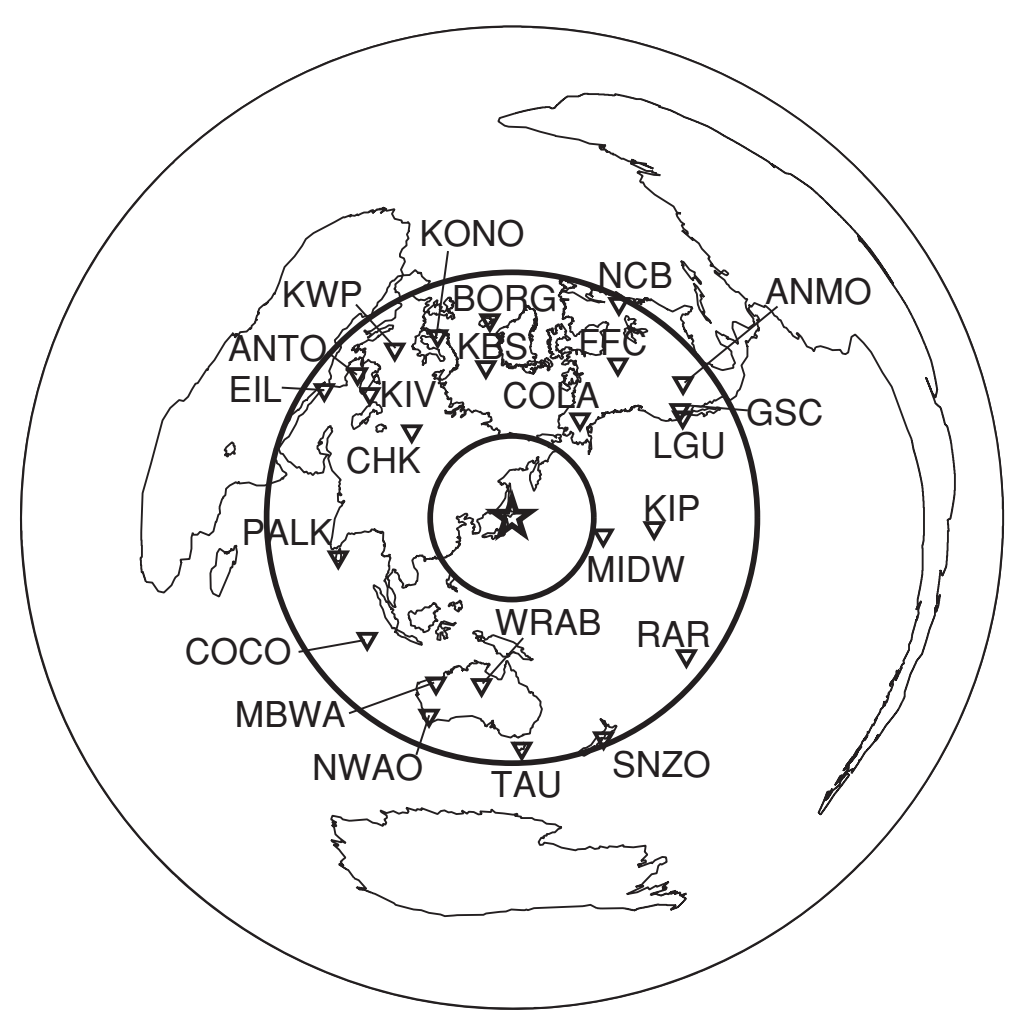

Fig. 2. Distribution of the stations used in this study plotted on a world map using the equidistant azimuthal projection. The center of the map is the epicenter of the 2003 Tokachi-oki earthquake. The smaller and larger circles stand for the epicentral distances of $30^{\circ}$ and $90^{\circ}$, respectively. 


\section{Method}

Inversion analysis of waveforms is performed for estimating slip distribution on a fault. The inversion scheme used in this study was originally developed by Hartzell and Heaton (1983). In the inversion procedure, a representative fault with fixed geometry and dimensions is initially chosen. The fault is then divided into small square areas (subfaults) of equal size. Rupture over the fault was assumed to propagate at a constant velocity away from the hypocenter.

For each subfault, Green's functions generated at all the stations are joined end to end to form a synthetics matrix G. This matrix, and similarly arranged observed records d, form an overdetermined system of linear equations $\mathbf{G m}=$ $\mathbf{d}$, where $\mathbf{m}$ is a solution vector containing the subfault dislocation weights required to reproduce the observations. An a priori data covariance matrix $\mathbf{C}_{\mathbf{s}}$ is applied to this equation system as a data scaling matrix. This data covariance matrix is diagonal and normalizes the observed waveforms to share the same peak amplitude. Thus each record has nearly equal weight in the inversion. Without this normalization, a leastsquares inversion would fit records of large amplitude very well and would tend to ignore records of smaller amplitude. Such a scheme can give biased results when trying to invert for a slip distribution (Hartzell and Heaton, 1983). A smoothness constraint is additionally imposed on the equation system by requiring that the Laplacian of slip distribution be zero for each subfault. In summary, the equation system to be solved can be written as

$$
\left(\begin{array}{c}
\mathbf{C}_{\mathbf{s}}^{-1} \mathbf{G} \\
\lambda \mathbf{S}
\end{array}\right) \mathbf{x}=\left(\begin{array}{c}
\mathbf{C}_{\mathbf{s}}^{-1} \mathbf{d} \\
0
\end{array}\right)
$$

where $\mathbf{S}$ represents the smoothing operator. Here $\lambda$ is the weight of the smoothness constraint.

This equation system is solved with a Householder leastsquares inversion scheme (Lawson and Hanson, 1974) that invokes a positivity constraint on the solution. The positivity constraint is imposed not only because it is physically reasonable but also because negative slips lead to destructive interference between subfaults, producing unstable solutions (Hartzell and Heaton, 1983).

The weight of the smoothness constraint is determined by performing several preliminary inversions with various weights. I do not use a mathematical criterion such as Akaike's Bayesian Information Criterion for determining the weight. The goal of this tuning is to apply as much smoothing as we can without significantly perturbing the overall fit to the observed waveforms. This results in the simplest possible solution allowed by the observed waveforms.

Green's functions are calculated with ray theory (e.g., Lay and Wallace, 1995). The geometrical spreading factors are calculated with the Jeffreys-Bullen Earth model. Anelastic attenuation is taken into account with Futterman's (1962) Q operator, and a value of 4.0 is assumed for $t^{*}$. The effect of both crustal structures of near-source and nearstation is also incorporated into the Green's functions. The near-source velocity structure is assumed to be horizontally stratified on the basis of seismic refraction survey by using ocean-bottom seismometers and explosions near the source region which were conducted by Iwasaki et al. (1989) (Ta-
Table 1. Velocity structure assumed in the near-source region.

\begin{tabular}{cccc}
\hline $\begin{array}{c}\text { Thickness } \\
(\mathrm{km})\end{array}$ & $\begin{array}{c}\mathrm{V}_{\mathrm{P}} \\
(\mathrm{km} / \mathrm{s})\end{array}$ & $\begin{array}{c}\mathrm{V}_{\mathrm{S}} \\
(\mathrm{km} / \mathrm{s})\end{array}$ & $\begin{array}{c}\rho \\
\left(\mathrm{g} / \mathrm{cm}^{3}\right)\end{array}$ \\
\hline 2.0 & 1.5 & 0.0 & 1.0 \\
1.0 & 1.8 & 0.55 & 1.8 \\
1.0 & 3.0 & 1.5 & 2.0 \\
5.0 & 4.7 & 2.5 & 2.1 \\
10.0 & 5.5 & 3.2 & 2.3 \\
5.0 & 6.8 & 3.5 & 2.5 \\
- & 7.9 & 4.6 & 3.3 \\
\hline
\end{tabular}

$\mathrm{V}_{\mathrm{P}}$ : P-wave velocity, $\mathrm{V}_{\mathrm{S}}$ : S-wave velocity, $\rho$ : density.

ble 1).

\section{Inversion with a Planar-Fault Model \\ 4.1 Fault model}

The fault plane is assumed to have a length of $150 \mathrm{~km}$ and a width of $140 \mathrm{~km}$ on the basis of the one-month aftershock distribution (Fig. 1). The fault is then divided into 15 subfault elements along strike and 14 elements downdip, giving each subfault $10 \mathrm{~km} \times 10 \mathrm{~km}$. The epicenter is fixed at the location preliminarily determined by the Japan Meteorological Agency $\left(41.780^{\circ} \mathrm{N}, 144.078^{\circ} \mathrm{E}\right)$. Incidentally, the location error does not heavily affect the results in this study. Here I use teleseismic body waves and do not try to fit the absolute time in the course of the inversion. As shown later, I have tried to find appropriate values for the focal mechanism (strike, dip and rake angles), hypocentral depth and rupture velocity using a grid search. A pair of parameters that give the least residual error was chosen as being appropriate. Here the residual error is defined as the square root of L2 norm of Eq. (1).

\subsection{Results}

Figure 3(a) shows the estimated slip distribution that gives the least residual error among the values that were checked. This slip distribution is obtained from a rupture velocity of $2.5 \mathrm{~km} / \mathrm{s}$, a hypocentral depth of $15 \mathrm{~km}$ and a fault plane with a strike of $230^{\circ}$, dip of $20^{\circ}$, and rake of $110^{\circ}$. The focal mechanism is quite similar to that derived from the preliminary analysis of static displacement measured with the GPS array (Geographical Survey Institute, 2003). Two patches of large slip (asperities) appear on the fault. One is shallow and near the hypocenter and the other is deep and located to the northwest (landward side) of the hypocenter. The deeper asperity is larger in both spatial size and amount of slip than the shallower one. The seismic moment and the moment magnitude are estimated to be $1.9 \times 10^{21} \mathrm{Nm}$ and 8.1 , respectively. The average slip over the fault is $1.4 \mathrm{~m}$.

The seismic moment rate function is displayed with a dashed line in Fig. 3(c). The shape of the rate function is simple and well-approximated with a triangle of a duration of $60 \mathrm{~s}$. The moment rate function reaches the peak value at about $24 \mathrm{~s}$.

Comparison of the observed waveforms and synthetic waveforms is shown in Fig. 4. The derived slip distribution can explain the observed waveforms well. However, a 
(a) Planar Fault

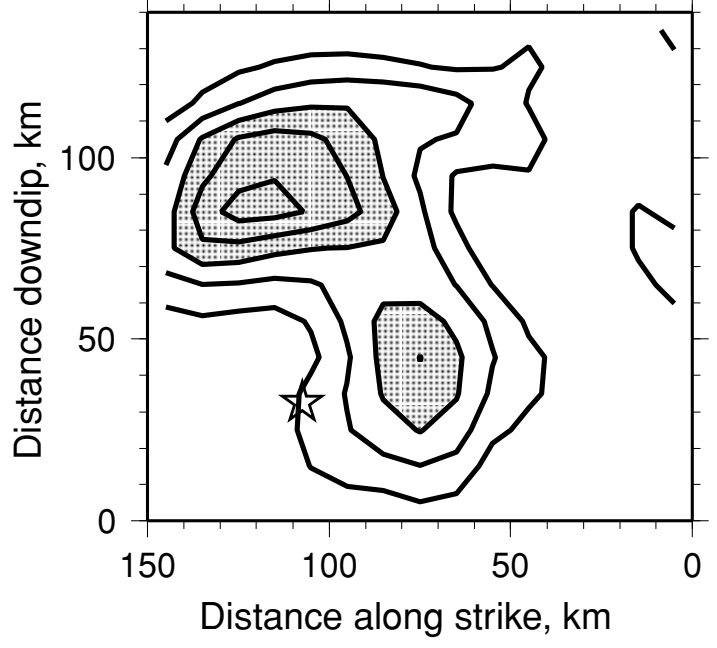

(b) Compound Fault
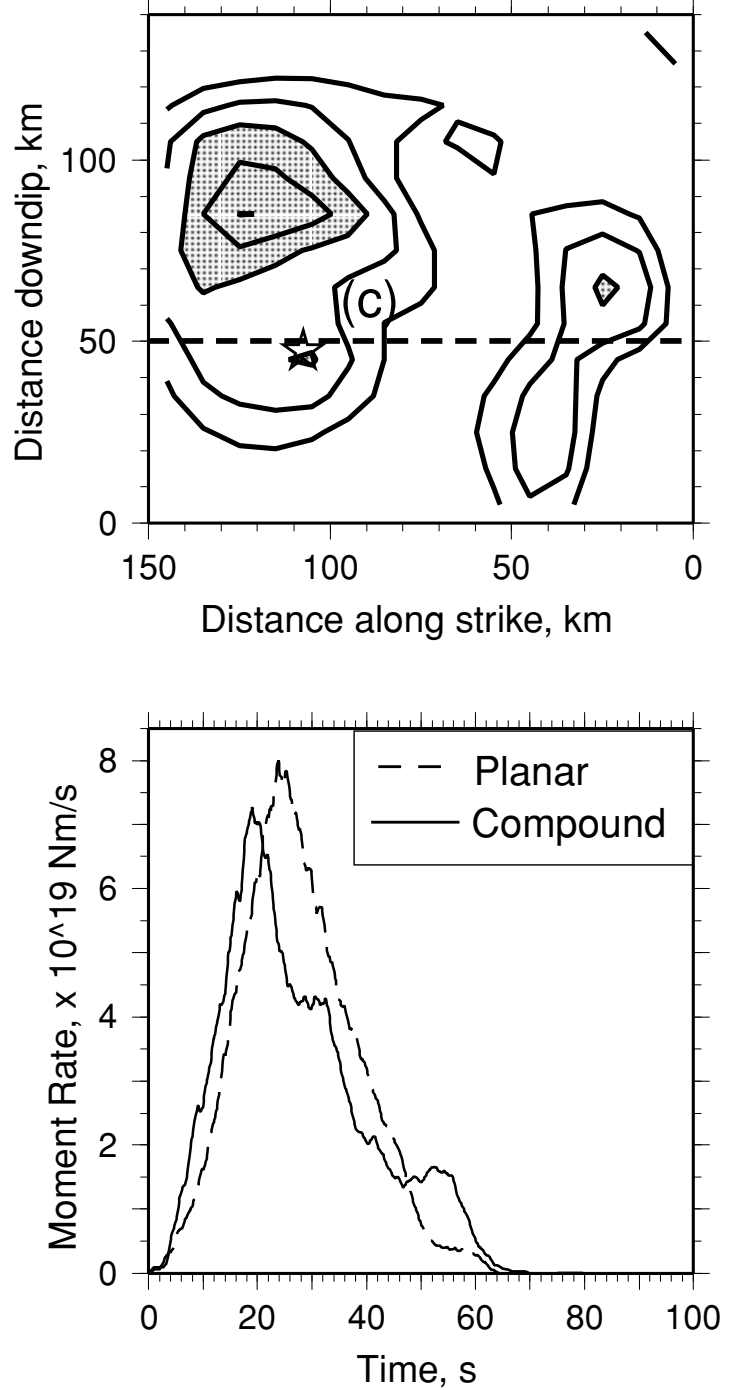

Fig. 3. Slip distributions obtained from a planar fault (a) and a compound fault (b). The contours start at $1 \mathrm{~m}$ and continue at $1 \mathrm{~m}$ intervals. Regions with slip larger than $3 \mathrm{~m}$ are stippled. The hypocenter is shown with a star, and the dashed line in the panel (b) stands for the hinge line. (c) Moment rate functions obtained from a planar fault (dashed line) and a compound fault (solid line). closer look at the waveforms reveals that the polarities of the initial part (10-20 s from the onset) of synthetic waveforms at the stations GSC, LGU, and SNZO do not match those of the observed waveforms.

Figure 5 shows contour maps of the residual error when changing the initially assumed fault parameters of a focal mechanism, rupture velocity and hypocentral depth. The contours in Fig. 5(a) are well-approximated with horizontally extended ellipses. This means that the fault strike is less sensitive than the fault dip in the present analysis. The contour lines in Fig. 5(b) are also well-approximated with horizontally extended ellipses. This means that the rake angle is less sensitive than the dip angle in the present analysis. Accordingly, the dip angle is the most sensitive of the three parameters. Figure 5(c) shows the results from various hypocentral depths and a rupture velocity with a fixed fault geometry. Although neither of the parameters are well-constrained, hypocentral depth of about 10-15 km seems preferable, and the preferred rupture velocity ranges between 2.5 and $3.0 \mathrm{~km} / \mathrm{s}$.

As mentioned before, a seismic refraction survey was conducted just above the source region (Iwasaki et al., 1989). This seismic survey shows that the dip angle of the plate interface at the shallower depth $(<20 \mathrm{~km})$ is about $5^{\circ}$. However, contour maps of residual error (Figs. 5(a) and (b)) show that a single planar fault with shallower dips $\left(5^{\circ}-15^{\circ}\right)$ yielded a much worse residual than the inversion with the planar fault of the dip angle of $20^{\circ}$. Therefore, a single planar fault with a low dip angle is not plausible.

\section{Inversion with a Compound-Fault Model}

\subsection{Fault model}

The compound fault assumed in this section consists of two planes that have the same strike but different dip angles. Hence, the fold extends along the strike as shown in Fig. 1. The dip angle of the shallower part is fixed at $5^{\circ}$ on the basis of the seismic refraction survey (Iwasaki et al., 1989) while the dip angle of the deeper plane varies during the inversion analysis. The overall dimension (i.e., length and width) of the compound fault is the same as that of the planar fault assumed in the previous section.

The inversion analysis with the compound-fault model is performed in two steps. In the first step, inversion analysis is repeated by fixing the hypocentral depth and rupture velocity and varying the fault geometry as mentioned below. In the second step, inversion analysis is repeated by fixing the fault geometry and varying the hypocentral depth and rupture velocity.

In the first step, the location of the fold and the dip angle of the deeper plane are varied. The location of the fold and the dip angle that give the least residual error are finally adopted. In the repeated inversions, the location of the fold changes from 40 to $80 \mathrm{~km}$, where the location is measured from the upper edge of the shallower part of the compound fault. The interval for changing the location is set to be $10 \mathrm{~km}$. The dip angle varies from 10 to $40^{\circ}$ with $5^{\circ}$ intervals. The adopted values of the location of the fold and dip angle is $50 \mathrm{~km}$ and $20^{\circ}$, respectively. These values are used in the second step, where the hypocentral depth and rupture velocities assumed for the two planes are varied 

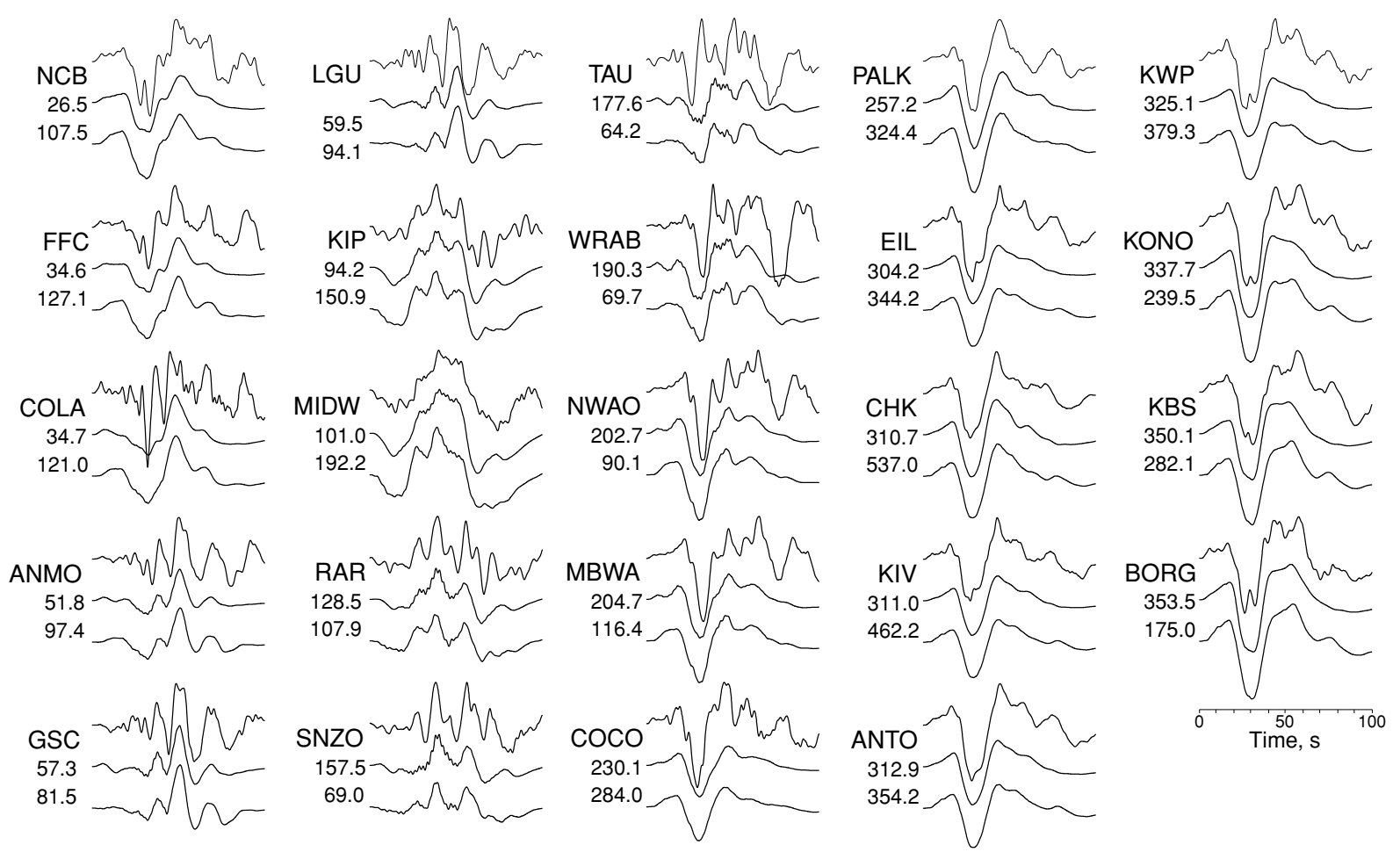

Fig. 4. Comparison of the observed waveforms (top trace), the synthetic waveforms resulting from the planar-fault model (middle trace) and the synthetic waveforms resulting from the compound-fault model (bottom trace). The origin of the time axis corresponds to the onset of P-wave at each station. Two numerals below a station code represent the azimuth measured clockwise from north (upper) and peak-to-peak amplitude of the observed waveform in microns (lower), respectively.
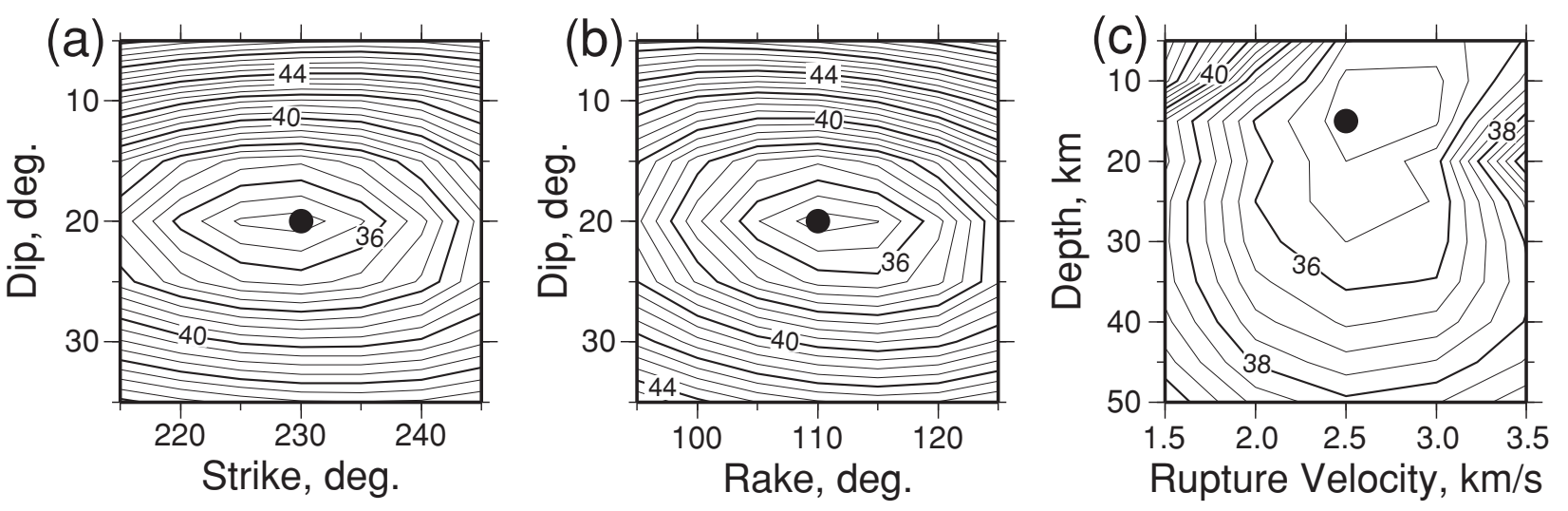

Fig. 5. Contours of residual error for different fault geometry, rupture velocity, and hypocentral depth. See the text the definition of residual error. Circles show the solution that gives the least residual error. (a) Plot against strike and dip angles with fixed rake angle of $110^{\circ}$, rupture velocity of $2.5 \mathrm{~km} / \mathrm{s}$, and hypocentral depth of $15 \mathrm{~km}$. (b) Plot against strike and rake angles with fixed dip angle of $20^{\circ}$, rupture velocity of $2.5 \mathrm{~km} / \mathrm{s}$, and hypocentral depth of $15 \mathrm{~km}$. (c) Plot against rupture velocity and hypocentral depth with fixed fault geometry. The strike, dip and rake angles are $230^{\circ}, 20^{\circ}, 110^{\circ}$, respectively.

separately, and the intervals are the same as those adopted in the inversion with a planar fault. A hypocentral depth of $30 \mathrm{~km}$ and rupture velocity of $1.5 \mathrm{~km} / \mathrm{s}$ for the shallower fault plane and $2.5 \mathrm{~km} / \mathrm{s}$ for the deeper fault plane yield the least residual error.

\subsection{Results}

Figure 3(b) shows the estimated slip distribution. This slip distribution is obtained when the hypocentral depth, the location of the hinge line, dip angle of the deeper plane, rupture velocity of the shallower plane and the rupture velocity of the deeper part are set to be $30 \mathrm{~km}, 50 \mathrm{~km}, 20^{\circ}, 1.5$ $\mathrm{km} / \mathrm{s}$ and $2.5 \mathrm{~km} / \mathrm{s}$, respectively. Two asperities are found on the compound fault. The major asperity is located in the downdip (landward side) of the hypocenter, and the minor asperity is located in the anti-strike direction (northeast) of the hypocenter. The maximum slips of the major and minor asperities reach 5 and $3 \mathrm{~m}$, respectively. The seismic moment and the moment magnitude are estimated to be $1.8 \times 10^{21} \mathrm{Nm}$ and 8.1 , respectively. The average slip over the fault is $1.2 \mathrm{~m}$.

When comparing the slip distribution of the compoundfault model with that of the planar-fault model, the land- 

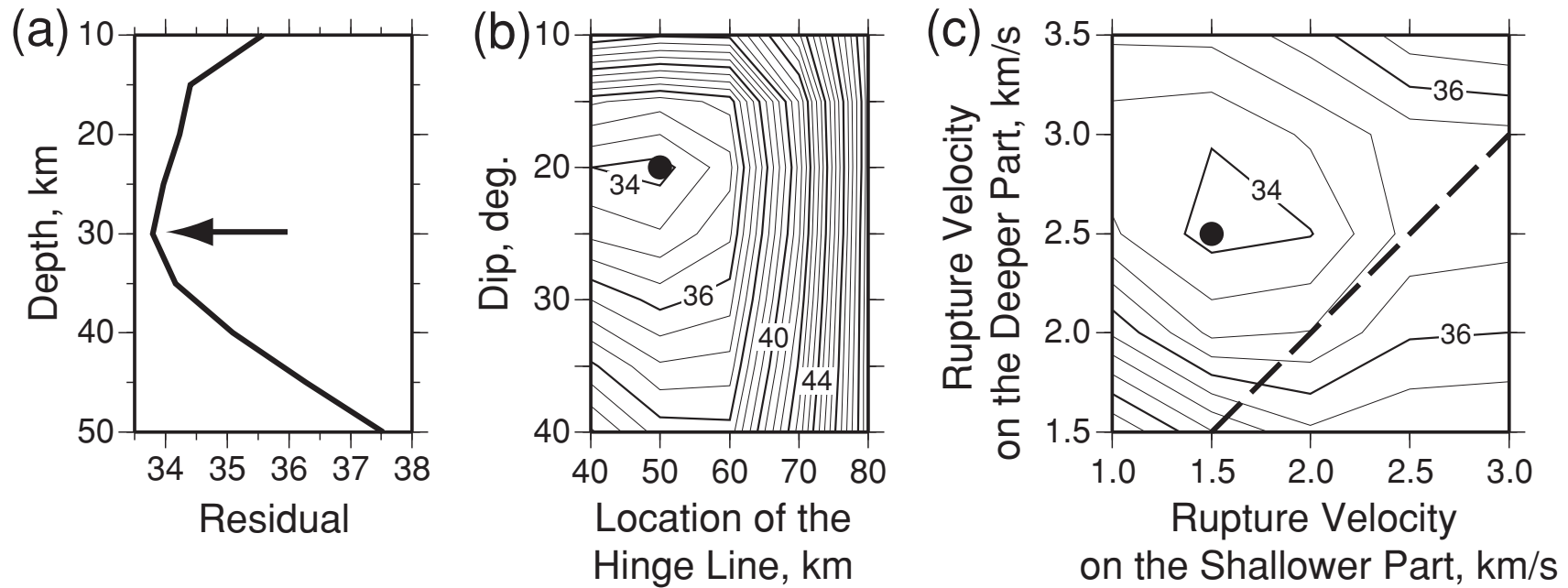

Fig. 6. Residual error for the compound-fault model with different fault geometry, rupture velocities assigned on each fault plane, and hypocentral depth. See the text for the definition of residual error. (a) Residual distribution for depth variation with fixed fault configuration and rupture velocity. The arrow means the least residual. (b) Contours against the dip angle of the deeper fault plane and the location of the hinged line with fixed strike angle $\left(230^{\circ}\right)$, rupture velocities $(1.5$ and $2.5 \mathrm{~km} / \mathrm{s}$ for the shallower and deeper fault plane, respectively), and hypocentral depth $(30 \mathrm{~km})$. The closed circle stands for the least residual. (c) Contours against rupture velocities with fixed hypocentral depth and fault configuration. Rupture velocities of the shallower fault and the deeper fault are equal to each other along the bold dashed line. The closed circle stands for the least residual.

ward asperity is quite similar to the deeper asperity of the planar-fault model in location, spatial extent, and slip amount (Fig. 3(a)). On the other hand, the asperity found near the hypocenter for the planar-fault model diminishes in the compound-fault model. The seismic moment and the average slip of the compound-fault model are slightly smaller than those of the planar-fault model.

The moment rate function of the compound-fault model (solid line in Fig. 3(c)) is more complex than that of the planar-fault model (dashed line in Fig. 3(c)). The moment rate function of the compound-fault model starts with simple growth, and reaches a peak value at about $20 \mathrm{~s}$. The moment rate function then decreases not monotonically but with two "landings" located at about 28-34 and 50-60 s. These "landings" come from the minor asperity, which extends across the hinge line. The rupture velocity of the deeper part is faster than that of the shallower part. Hence, the deeper part of the minor asperity contributes the earlier "landing" and the shallower part contributes the later "landing."

The synthetic waveforms from the compound-fault model explain the observed waveforms well (Fig. 4). In addition, the residual error of the compound-fault model is smaller than that of the planar-fault model. The initial polarities at stations GSC, LGU, and SNZO are better explained with the compound-fault model than with the planar-fault model. Hence, I believe that this compound-fault model is preferable to the planar-fault model.

Figure 6 shows the residual error for various fault configurations, hypocentral depths and rupture velocities. A hypocentral depth of $30 \mathrm{~km}$ gives the least residual (Fig. 6(a)). The residual changes gradually between 15 and $35 \mathrm{~km}$ while the residual rapidly increases outside this range. Figure 6(b) shows that the residual becomes much worse as the location of the hinge line becomes deeper and the dip angle becomes shallower. A faster velocity on the deeper part and a slower velocity on the shallower part tends to yields a smaller residual error (Fig. 6(c)).

This distribution of rupture velocity seems reasonable when we take into consideration that the rigidity along the plate interface increases with depth (Bilek and Lay, 2000) and the rupture velocity is empirically found to be close to the S-wave velocity (Geller, 1976). However, the validity of the low velocity at the shallower part must be carefully investigated. The largest slip at the shallower part appears far from the hypocenter. This means that the slip on the shallow part mainly contributes to the later part $(\approx 70 \mathrm{~s})$ of the waveforms (Fig. 4). Since inaccurate modeling of the near-source velocity structure makes it difficult to model the later part of the observed waveforms (Wiens, 1987) and sometimes yields a biased slip distribution (Yoshida, 1992), the minor asperity on the compound-fault model may be biased. More accurate modeling of the near-source velocity structure will be required in order to discuss the validityof the shallow asperity and the low rupture velocity.

\section{Concluding Remarks}

I have, here, demonstrated that the fault geometry could greatly affect the slip distribution of the 2003 Tokachi-oki earthquake. This suggests that it is important to incorporate realistic dip variation into a fault model in order to construct a reliable fault model from teleseismic body waves. We should pay attention to this dependence before characterizing and discussing the nature of the slip distribution of an earthquake, since the dip angle often varies with depth (e.g., Hasegawa et al., 1994).

Acknowledgments. I am grateful to the Incorporated Research Institutions for Seismology (IRIS) and the IRIS Data Management Center for providing broad-band seismograms. Discussions with Yuko Kase and Haruko Sekiguchi was helpful. Comments by two anonymous reviewers greatly improved the manuscript. The hypocenters are determined and provided by the Japan Meteorological Agency. The data used in the determination are provided 
by the following universities and organizations: Hokkaido University, Hirosaki University, Tohoku University, the University of Tokyo, Nagoya University, Kyoto University, Kochi University, Kyushu University, Kagoshima University, Japan Meteorological Agency, National Institute for Earth Science and Disaster Prevention, Japan Marine Science and Technology Center, and National Institute for Advanced Industrial Science and Technology. Some figures are prepared with the Generic Mapping Tools (Wessel and Smith, 1998).

\section{References}

Bilek, S. L. and T. Lay, Depth dependent rupture properties in circumPacific subduction zone, in GeoComplexity and the Physics of Earthquakes, edited by J. B. Rundle, D. L. Turcotte, and W. Klein, pp. 165186, American Geophysical Union, Washington D.C., 2000.

Futterman, W. I., Dispersive body waves, J. Geophys. Res., 67, 5279-5291, 1962.

Geller, R. J., Scaling relations for earthquake source parameters and magnitudes, Bull. Seism. Soc. Am., 66, 1501-1523, 1976.

Geographical Survey Institute, Preliminary analysis of nationwide GPS array for a fault model of the 2003 Tokachi-oki earthquake, http:// www.gsi.go.jp/WNEW/PRESS-RELEASE/2003/0926-2.htm, 2003 (in Japanese).

Hartzell, S. H. and T. H. Heaton, Inversion of strong ground motion and teleseismic waveform data for the fault rupture history of the 1979 Imperial Valley, California, earthquake, Bull. Seism. Soc. Am., 73, 15531583, 1983.

Hasegawa, A., S. Horiuchi, and N. Umino, Seismic structure of the northeastern Japan convergent margin: A synthesis, J. Geophys. Res., 99, 22295-22311, 1994.

Iwasaki, T., H. Shiobara, A. Nishizawa, T. Kanazawa, K. Suyehiro, N. Hirata, T. Urabe, and H. Shimamura, A detailed subduction structure in the Kuril Trench deduced from ocean bottom seismographic refraction studies, Tectonophysics, 165, 315-336, 1989.

Lawson, C. L. and R. J. Hanson, Solving Least Squares Problems, 340 pp., Prentice-Hall, 1974.

Lay, T. and T. C. Wallace, Modern Global Seismology, 521 pp., Academic Press, San Diego, California, 1995.

Wessel, P. and W. H. F. Smith, New, improved version of Generic Mapping Tools released, Eos, 79, 579, 1998.

Wiens, D. A., Effects of near source bathymetry on teleseismic P waveforms, Geophys. Res. Lett., 14, 761-764, 1987.

Yoshida, S., Waveform inversion for rupture process using a non-flat seafloor model: application to 1986 Andreanof Islands and 1985 Chile earthquakes, Tectonophysics, 211, 45-59, 1992.

H. Horikawa (e-mail: h.horikawa@aist.go.jp) 